\title{
Comparison of individuals consuming natural spring water and tap water in terms of urinary tract stone disease
}

\author{
Mustafa Resorlu ${ }^{1}$, Muhammet Arslan ${ }^{2}$, Eylem Burcu Resorlu ${ }^{3}$, Murat Tolga Gulpinar ${ }^{4}$, \\ Gurhan Adam ${ }^{1}$, Eyup Burak Sancak ${ }^{4}$, Alpaslan Akbas ${ }^{4}$, Nilufer Aylanc ${ }^{1}$, Huseyin Ozdemir ${ }^{1}$ \\ ${ }^{1}$ Department of Radiology, Canakkale Onsekiz Mart University, Faculty of Medicine, Canakkale, Turkey; \\ 2 Department of Radiology, Vefa Hospital, Manisa, Turkey; \\ ${ }^{3}$ Department of Radiology, Canakkale State Hospital, Canakkale, Turkey; \\ ${ }^{4}$ Department of Urology, Canakkale Onsekiz Mart University, Faculty of Medicine, Canakkale, Turkey.
}

\begin{abstract}
Summary Objectives: To compare individuals consuming natural spring water and tap water in terms of presence of urinary tract stone disease. Patients and methods: Patients were divided into two groups on the basis of the type of water: tap water (Group I) vs natural spring water consumers (Group II). The two groups were compared in terms of presence of urolithiasis. In addition to the type of water consumed, participants were investigated in terms of age, sex, occupation, body mass index (BMI) and presence of hypertension (HT) and diabetes mellitus in order to evaluate if they constituted a risk factor for urolithiasis.

Results: Two hundred fifty-nine patients consuming tap water and 254 consuming natural spring water were included in this study. Presence of urinary stone disease was determined in $27 \%$ of patients in Group I and 26\% of Group II $(p=0.794)$. At multivariate analysis involving all variables that might be correlated with the presence of urolithiasis; male gender, high BMI and presence of HT emerged as being significantly associated with urolithiasis. Conclusions: Although we showed that male gender, presence of HT and high BMI affect stone formation, no difference was demonstated in terms of presence of stone among patients consuming tap or natural spring water
\end{abstract}

KEY WORDS: Tap water; Natural spring water; Ultrasound; Urolithiasis.

Submitted 3 July 2014; Accepted 14 July 2014

\section{INTRODUCTION}

Urinary system stone disease is a common pathology, with a lifetime prevalence across the world of between $1 \%$ and $15 \%(1)$. The disease is more common in some geographical regions probably in relation with various genetic and environmental factors. Considering environmental factors alone, stone disease is more common in mountaineous areas and in people living in dry and hot climatic conditions, such as deserts and tropical regions (2). Studies have implicated temperature-related fluid loss from the body and rise in vitamin D stimulated by solar rays as the main reasons for this $(3,4)$.
Several studies have proved that increasing daily fluid intake plays a protective role against stone formation by leading to diuresis and preventing supersaturation of stone components in urine (5-7). As much as the amount of fluid consumed, however, several studies have also considered the effect on stone formation of mineral content, electrolyte level, hardness and $\mathrm{pH}$ level of water consumed (8-15). However, no studies to date have investigated the widespread popular idea that consumption of chlorinated tap water can lead to stone disease. In order to answer that question, we used renal ultrasound (US) to compare individuals consuming natural spring water or tap water in terms of presence of stone in the urinary system.

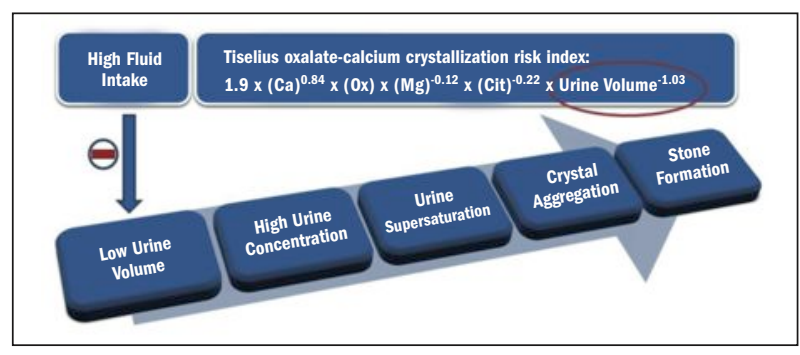

\section{Materials AND METHODS}

Study population

Five hundred thirteen patients aged over 18 who underwent urinary system US due to abdominal or flank pain and meet study conditions were included in the study following approval of its design by the Çanakkale Onsekiz Mart University Ethical Committee. Subjects with renal malformation that might constitute a risk factor for urinary stone formation (horseshoe kidney, polycystic renal disease, malrotated or ectopic kidney, ureteropelvic junction obstruction etc.), with known glomerular or tubular renal disease or a family predisposition (with stone first detected in childhood) to stone disease were excluded from the study. Patients were divided into two groups on the basis of the type of water they had principally consumed in the previous 2 years: those consuming tap water (Group I) and those consuming natural spring water (Group II). Patients drinking both types of water or had changed the type of 
water consumed over the preceding 2 years or stating to consumed less than 7 glasses of water a day $(<1.5$ L/day $)$ were excluded. In addition to the type of water consumed, demographic data such as participants' age, sex, occupation, body mass index (BMI) and presence of chronic diseases such as hypertension (HT) and diabetes mellitus (DM) were recorded. All these variables were investigated in terms of whether or not they constituted a risk factor for presence of stone in the urinary system.

\section{Ultrasound measurements}

All examinations were performed by radiologists with experience of ultrasound. Sonographic examinations were performed with gray scale ultrasound machines (Toshiba Aplio XG and General Electric Logiq 9) using two convex transducers with $3.5 \mathrm{MHz}, 4.0 \mathrm{MHz}$ frequency. The presence of the stone was defined as presence of an echogenic image with or without posterior acoustic shadowing, clearly located within the urinary tract.

\section{Statistical analysis}

All statistical analyses were performed using SPSS, version 16.0. All values are shown as mean \pm standard deviation. Comparisons were performed using the chi-square test. Differences between groups were considered statistically significant at $\mathrm{p}<0.05$.

\section{RESULTS}

Two hundred fifty-nine patients consuming tap water (Group I) and 254 consuming natural spring water (Group II) were included in the study. In terms of gender, $52 \%$ of males stated that they used to drink tap water and 48\% natural spring water, while $49 \%$ of women used to drink tap water and $51 \%$ natural spring water. Mean age of patients was 52.2 (18-88) years in group I and 48.6 (1886) in Group II $(p=0.75)$. Mean BMI values were 25.7 $\mathrm{kg} / \mathrm{m}^{2}$ in Group I and $26.2 \mathrm{~kg} / \mathrm{m}^{2}$ in Group II ( $\left.\mathrm{p}=0.58\right)$. In terms of chronic diseases, HT was determined in $22 \%$ and DM in $17 \%$ of patients in group I, and in $16 \%$ and $12 \%$, respectively, of those in Group II. Stone was detected in $26 \%(\mathrm{n}=145)$ of the patients in the study, in $33 \%$ of men and $18 \%$ of women $(\mathrm{p}<0.001)$. Presence of stone in the urinary system was determined in $27 \%$ of patients in Group I and 26\% of Group II ( $p=0.794)$. Mean BMI of the patients with stone in the urinary system was $27.2 \mathrm{~kg} / \mathrm{m}^{2}$ whereas it was $25.5 \mathrm{~kg} / \mathrm{m}^{2}$ in those with no stone. DM was observed in $17 \%$ and HT in $31 \%$ of the patients with stone and in $14 \%$ and $15 \%$, respectively, in those with no stone. At multivariate analysis involving all variables that might be correlated with the presence of a stone in the urinary system, male gender and presence of HT emerged as being significantly associated with urolithiasis. Variables such as age, occupation, type of water consumed and presence of DM were not risk factors for development of stone.

\section{Conclusions}

In this study we therefore investigated whether there is any association between consumption of tap or natural spring water and urolithiasis in patients receiving US due to abdominal or flank pain. Although we showed that male gender, presence of HT and high BMI affect the risk of stone formation, no difference was determined in terms of presence of stone among patients consuming tap versus natural spring water.

\section{REFERENCES}

1. Curhan GC. Epidemiology of stone disease. Urol Clin North Am. 2007; 34:287-93.

2. Soucie JM, Thun MJ, Coates RJ, et al. Demographics and geographic variability of kidney stones in the United States. Kidney Int. 1994; 46:893-9

3. Curhan GC, Willett WC, Rimm EB, et al. A prospective study of dietary calcium and other nutrients and the risk of symptomatic kidney stones. N Engl J Med. 1993; 328:833-8.

4. Urinary volume, water and recurrences in idiopathic calcium nephrolithiasis: a 5-year randomized prospective study. J Urol. 1996; 155:839-43.

5. Borghi L, Meschi T, Amato F, et al. Urinary volume, water and recurrences in idiopathic calcium nephrolithiasis: a 5-year randomized prospective study. J Urol. 1996; 155:839-43.

6. Lotan Y, Daudon M, Bruye F, et al. Impact of fluid intake in the prevention of urinary system diseases: a brief review. Curr Opin Nephrol Hypertens. 2013; 22(Suppl):1-10.

7. Parks JH, Goldfischer ER, Coe FL. Changes in urine volüme accomplished by physicians treating nephrolithisis. J Urol. 2003; 169:863-6.

8. Aras B, Kalfazade N, Tugcu V, et al. Can lemon juice be an alternative to potassium citrate in the treatment of urinary calcium stones in patients with hypocitraturia? A prospective randomized study. Urol Res. 2008; 36:313-7.

9. Koff SG, Paquette EL, Cullen J, et al. Comparison between lemonade and potassium citrate and impact on urine $\mathrm{PH}$ and 24-hour urine parameters in patients with kidney stone formation. Urology. 2007; 69:1013-6.

10. Penniston KL, Steele TH, Nakada SY. Lemonade therapy increases urinary citrate and urine volumes in patients with recurrent calcium oxalate stone formation. Urology. 2007; 70:856-60.

11. Goldfarb DS, Asplin JR. Effect of grapefruit juice on urinary lithogenicity. J Urol. 2001; 166:263-7.

12. Shuster J, Finlayson B, Scheaffer R, et al. Water hardness and urinary stone disease. J Urol. 1982; 128:422-5.

13. Bellizi V, De Nicola L, Minutolo R, et al. Effects of water hardness on urinary risk factors for kidney stones in patients with idiopathic nephrolithiasis. Nephron 1999; 81 (Suppl1):66-70.

14. Rodgers AL. Effect of mineral water containing calcium and magnesium on calcium oxalate urolithiasis risk factors. Urol Int. 1997; 58:93-9.

15. Massey LK, Sutton RA. Acute caffeine effects on urine composition and calcium kidney stone risk in calcium stone formers. J Urol. 2004; 172:555-8.

\section{Correspondence}

Mustafa Resorlu, MD (Corresponding Author)

mustafaresorlu77@gmail.com

Gurhan Adam, MD - Huseyin Ozdemir, MD - Nilufer Aylanc, MD Department of Radiology, Canakkale Onsekiz Mart University, Faculty of Medicine, Canakkale Onsekiz Mart Universitesi,

Terzioglu Yerleskesi - Barbaros Mh, 17100, Canakkale, Turkey

Muhammet Arslan, MD

Department of Radiology, Vefa Hospital, Manisa, Turkey

Eylem Burcu Resorlu, MD

Department of Radiology, Canakkale State Hospital, Canakkale, Turkey

Murat Tolga Gulpinar, MD - Eyup Burak Sancak, MD - Alpaslan Akbas, MD Department of Urology, Canakkale Onsekiz Mart University,

Faculty of Medicine, Canakkale, Turkey 